\title{
Financial and operational benefit of improving patient status assignment and observation services across seven hospitals in the United States
}

Amar V. Munsiff;, G. Scott Dillon

Hospital Physician Advisors, Cary, NC, United States

Received: March 30, 2021

DOI: $10.5430 /$ jha.v10n3p17
Accepted: April 30, 2021

Online Published: May 10, 2021

\begin{abstract}
Objective: This aim of this project was to assess, develop and implement a paradigm for patient status assignment and more efficiently provide observation services. Patients who require hospitalization in the United States may remain an outpatient receiving observation services in the hospital, instead of inpatient status. Accurate and justifiable designation of patients to the right classification is of paramount importance because observation stays are reimbursed significantly less than inpatient admissions, incurring financial losses for hospitals, and sometimes patients.

Methods: We reviewed the processes for patient status assignment and observation service delivery at seven hospitals over a 12 month period for each facility between February 2017 and December 2020, conducted interviews with key stakeholders, and reviewed medical records for medical necessity documentation and accuracy of patient status designation. We implemented a bundle of interventions to improve accurate patient status assignment and operational performance, such as the length of stay and proportion of patients undergoing status changes.

Results: At all hospitals we achieved decreases in the proportion of patients assigned to observation services ( $38 \%$ to $17 \%, p$ $<.001$ ), average observation patients' length of stay (from 34 to 23 hours), and average daily observation census (from 24 to 12 patients). The accuracy of initial status assignment and medical necessity documentation increased, with a decrease in the proportion of hospitalized patients undergoing any status change $(p<.001$ for all). The annual post-intervention financial gain ranged from $\$ 2.5 \mathrm{M}$ to $\$ 20.8 \mathrm{M}$.

Conclusions: A comprehensive bundle of interventions achieved large operational and financial improvements in observation service delivery at hospitals of various sizes in the US.
\end{abstract}

Key Words: Patient status, Observation, Clinical decision unit, Emergency medicine, Hospital medicine, Physician advisor

\section{INTRODUCTION}

Observation services in the hospital are defined by Centers for Medicare and Medicaid Services (CMS) as "a welldefined set of specific, clinically appropriate services, which include ongoing short-term treatment, assessment, and reassessment before a decision can be made regarding whether patients require further treatment as hospital inpatients or if they are able to be discharged from the hospital. In a majority of cases, the decision whether to discharge a patient from observation care or to admit the patient as an inpatient can be made in less than 24 hours, and sometimes require up to 48 hours". ${ }^{[1]}$ Since most emergency department visits are under 6 hours, and inpatients discharged within 24h are deemed as avoidable admissions, a reimbursable, outpatient

*Correspondence: Amar V. Munsiff; Email: AVMunsiff@gmail.com; Address: PO Box 517, Cary, NC 27512, United States. 
status for these patients needing a 6-24 hour hospital stay was welcomed by hospital administrations. However, physicians, hospitals, payers and auditors disagree as to which patients need an observation or inpatient stay, and how much each is reimbursed. ${ }^{[2,3]}$

A physician's assessment of medical necessity was designated by CMS as the means for choosing between observation and inpatient status, and is also a fundamental tenet held by other insurers. To assist in choosing between "observation care" and "inpatient" status, CMS developed the "2-midnight rule": inpatient status is "based upon the physician's expectation of the required duration of medically necessary hospital services at the time the inpatient order is written and the formal admission process begins."[4] Other insurance carriers have additional unique and often proprietary criteria for the definition of inpatient and observation services, sometimes based on utilization screening guidelines such as Milliman

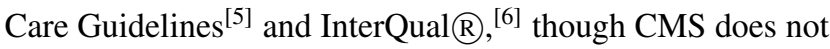
endorse their use.

The number of Medicare patients and veterans hospitalized for observation services has gradually increased. ${ }^{[7-9]}$ Several reports have demonstrated increasing utilization of observation services, ${ }^{[10]}$ and an increasing proportion of observation stays greater than 24 hours for commercially insured patients. ${ }^{[1,12]}$ Outpatient status for observation services has several implications for clinical care and cost to patients, hospitals and insurance carriers alike. ${ }^{[13,14]}$

Previous reports ${ }^{[4,9,10,15]}$ reporting on the epidemiology and utilization of observation services by private and public payers assumed that the designation of observation or inpatient status was done correctly. However, none assessed if medical necessity was documented, the accuracy of patient status assignment, and the financial impact of incorrect status assignments. We assessed seven hospitals with high rates of patients receiving medical observation services. The purpose of this study was to determine if improving operational efficiency of observation services and medical documentation of patient status assignment using a standardized approach can lead to financial gains.

\section{METHODS}

\subsection{Design and sample}

Between February 2017 and December 2020, we reviewed the processes for patient status assignment and observation service delivery at seven hospitals in Georgia, Illinois, Indiana, Maryland, Nebraska, New York and Ohio (see Table 1). The team was comprised of a physician executive and a healthcare executive, as well as knowledgeable experts in revenue cycle, hospital finance, utilization review (UR), care management (CM) and nursing. Each hospital determined that ethics committee review was not necessary as it was classified as a quality improvement project.

Table 1. Characteristics of hospitals

\begin{tabular}{|c|c|c|c|c|c|c|c|}
\hline & Hospital 1 & Hospital 2 & Hospital 3 & Hospital 4 & Hospital 5 & Hospital 6 & Hospital 7 \\
\hline Hospital Type & $\begin{array}{l}\text { Voluntary, } \\
\text { Nonprofit, } \\
\text { Community, Urban }\end{array}$ & $\begin{array}{l}\text { Voluntary, } \\
\text { Nonprofit, } \\
\text { Community, Rural }\end{array}$ & $\begin{array}{l}\text { County, Nonprofit, } \\
\text { Community, Rural }\end{array}$ & $\begin{array}{l}\text { Voluntary, } \\
\text { Nonprofit, Tertiary, } \\
\text { Urban }\end{array}$ & $\begin{array}{l}\text { Voluntary, } \\
\text { Nonprofit, } \\
\text { Community, Urban }\end{array}$ & $\begin{array}{l}\text { Voluntary, } \\
\text { Nonprofit, } \\
\text { Community, Urban }\end{array}$ & $\begin{array}{l}\text { Voluntary, } \\
\text { Nonprofit, } \\
\text { Community, Urban }\end{array}$ \\
\hline $\begin{array}{l}\text { Gross Annual Patient } \\
\text { Revenue }\end{array}$ & $\$ 666.7 \mathrm{M}$ & $\$ 419.2 \mathrm{M}$ & $\$ 593.2 \mathrm{M}$ & $\$ 1,662.9 \mathrm{M}$ & $\$ 1,600.6 \mathrm{M}$ & $\$ 629.7 \mathrm{M}$ & $\$ 338.1 \mathrm{M}$ \\
\hline \# of staffed beds & 232 & 94 & 144 & 449 & 210 & 300 & 233 \\
\hline $\begin{array}{l}\text { Total Annual } \\
\text { Discharges }\end{array}$ & 6191 & 6018 & 8063 & 14050 & 5559 & 14351 & 15975 \\
\hline $\begin{array}{l}\text { Average Inpatient LOS, } \\
\text { days }\end{array}$ & 6.4 & 5.08 & 5.5 & 5.6 & 4.8 & 4.4 & 4.4 \\
\hline Designated OBS unit? & No & Yes & No & Yes & No & No & yes \\
\hline $\begin{array}{l}\text { ED Trauma } \\
\text { Designation }\end{array}$ & Level I & Level III & Level III & Level II & Level II & Level V & Level II \\
\hline $\begin{array}{l}\text { Hospital Employed vs } \\
\text { Contracted Hospitalist } \\
\text { Program }\end{array}$ & Hospital Employed & Hospital Employed & Hospital Employed & Hospital Employed & $\begin{array}{l}\text { Hospital Employed, } \\
\text { Contracted, Private } \\
\text { Physicians }\end{array}$ & $\begin{array}{l}\text { Hospital Employed, } \\
\text { Contracted, Private } \\
\text { Physicians }\end{array}$ & $\begin{array}{l}\text { Hospital Employed, } \\
\text { Contracted, Private } \\
\text { Physicians }\end{array}$ \\
\hline
\end{tabular}

This was an observational study with a pre- and postintervention phase. We conducted interviews with key stakeholders, using structured questionnaires for each subject matter: payor relations, knowledge gap and documentation, and communications and handoffs (see Figure 1). Interviews focused on identifying local historical trends that contributed to the current state of patient status attribution, the perceived strengths and barriers to process improvement, and the actual systematic process of patient status assignment and conversion. We observed the workflow and handoffs in the ED and medical-surgical inpatient units to determine how policies and procedures were implemented. Responses from staff and our observations were recorded and summarized in this report. 
1. Interview key hospital stakeholders:

a. C-suite executive leadership; medical and nursing directors, Hospitalist \& ED directors; physician advisors and medical staff leadership; revenue cycle managers; members of the medical, nursing, care management, and utilization review staff; and clinical documentation specialists

2. Review Patient Operations with Management

3. Observe Front-line staff to learn daily operations

4. Conduct multidisciplinary review of medical charts for presence of medical necessity documentation

5. Review utilization, payer mix, reimbursement $\&$ denials data trends for previous 24 months:

a. Total daily medical hospitalizations from ED

b. Total daily Inpatient medical hospitalizations

c. Total daily observation medical hospitalizations

d. Total daily medical discharges from ED

e. Total daily Inpatient medical discharges

f. Total daily observation medical discharges

g. Observation length of stay

h. Staffing schedules

i. \# of each type of patient status conversion, daily

j. \# of MRI, ECHOs, EGDs, subspecialty consults, and therapeutic evaluations for observation patients

6. Review daily observation \& new admitted Inpatient Census for documentation of medical necessity, 1 week/month for 3 months, then 3 days/month for 12 months, post-intervention

Figure 1. Program evaluation

\subsection{Data sampling}

An initial sample of forty medical charts from the previous twelve months was chosen randomly in each hospital, and were reviewed to assess documentation by medical providers, care managers and utilization review staff for justifying the chosen patient status: specifically, if severity of illness, intensity of services, and/or risk of disease to the patient were noted. The reviews were done in a multidisciplinary fashion by the institution's utilization review nurse, physician advisor or chair of Utilization Committee, and an independent physician who were all blinded to the patients' assigned status and identity.

We reviewed 46,294 individual closed Medicare, Medicare Advantage, Medicaid, and private payer inpatient (28,967, $63 \%)$ and observation $(17,327,37 \%)$ patient financial accounts from the previous 24-month period across all seven facilities to determine the facility-specific average revenue for inpatient admission and observation services on the adult medical service. These cases excluded surgical, pediatric, obstetric, newborn, rehabilitation, and psychiatric patients. We calculated the estimated lost revenue had the medical encounter been assigned the status as determined by the team of multidisciplinary reviewers described above: the actual total patient revenue was deducted from the potential revenue to determine the estimated financial loss on a facility specific basis.

\subsection{Intervention}

At each hospital, we implemented the same bundle of operational systems and administrative tools, which re-aligned staff roles to facilitate medical necessity documentation by medical and CM/UM staff, and efficiently deliver observation services (see Figure 2). A key portion of our intervention was education of physicians, care managers, nurses, utilization review staff, and administrative staff about the definitions of patient status, medical decision-making, and the components of documentation for appropriately justifying the chosen patient status. The bundle included prompts for medical and $\mathrm{CM} / \mathrm{UM}$ providers to document status justification at the time of hospitalization, thus facilitating responses to anticipated insurance denials. Existing staffing was reconfigured to station a utilization review care manager in the ED to assist correct patient status designation and its documentation. Additionally, medical staff was re-organized to allow a dedicated medical provider for observation patients. 
1. Motivational Leadership

a. Administrative Leadership explains the goal \& impact

b. Medical Leadership explains the operational rationale

c. Identify Project Team (e.g., ED liaison, Physician Advisor, Care Management and Utilization Review staff)

2. 3-stage mandatory education for C-suite, and Medical, Nursing, UR and Compliance staff on:

a. Basic terminology and regulations governing patient status

b. Documenting Medical Necessity and medical decision making

c. Case Reviews demonstrating medical necessity documentation

3. Facilitate initial patient status determination in a 3-way conversation between ED provider, Inpatient provider, and $\mathrm{UM} / \mathrm{CM}$ nurse

4. Establish geographic cohorting of observation patients

5. Provide dedicated medical \& nursing staff for observation patients

6. Re-organize staff duties to support care progression instead of stagnation

a. Conduct multidisciplinary rounds twice daily

b. Assign high priority for tests for observation patients

c. Arrange prompt subspecialty consultation upon discharge instead of during hospitalization, if safe

7. Daily secondary review of all observation patients by Physician Advisor

8. Establish Patient Status Dashboards:

a. Operational Dashboard to track standard metrics for observation patients, including status conversions, especially from inpatient to observation.

b. Financial Dashboard, including denials, revenue cycle management, and aftercare.

9. Integrate the Project Leadership Team into the Hospital committee structure:

a. Monitor metrics monthly to identify actionable trends

b. Issue monthly reports to Medical Staff, UM, \& Quality committees

10. Update entire organization with periodic progress reports.

Figure 2. Patient status bundle

\subsection{Outcome measures}

Finally, we re-organized data collection and tabulation for patient status assignments, culminating in a patient status dashboard to share key metrics with the staff on a regular basis. These metrics were measured pre-intervention and post-intervention: proportion of patients admitted as observation and inpatient, number of status conversions, length of stay (LOS), number of 1-day inpatient stays, discharge order to departure time, ED admit decision to ED departure time, and proportion of observation patients off the observation unit. Patient status accuracy was defined as concurrence between medical provider, physician advisor, and UR staff on the initial patient status without a need for status conversion, and the proportion of accurate status conversions was followed on the dashboard. After implementing the interventions, we reviewed medical records of all newly admitted inpatients and all observation patients for 1 week each month for 3 months, and then 3 days a month thereafter. These metrics were compared at baseline and at 12 months post-intervention.

\subsection{Statistical analysis}

We calculated confidence intervals for each of these metrics, pre- and post-intervention proportions for each hospital, and confidence intervals for all of the hospitals combined. These calculations used the normal approximation to the binomial calculation for confidence intervals (Wald's Interval) as the samples and proportions are relatively large. ${ }^{[16]}$ Then, to assess the scope of pre- vs post-differences, we constructed confidence intervals for the differences between the two proportions for each measure, again using normal approximations. Finally, p-values were assessed for each confidence interval. ${ }^{[17]}$

\section{RESULTS}

\subsection{Baseline measures}

The key characteristics of seven hospitals are shown in Table 1. All were voluntary, non-profit hospitals, with 94 to 631-beds, with a range of 6,191 to 18,063 discharges over 12 months. Three hospitals had an established Observation Unit. All of the hospitals had employed hospitalists, though three had hybrid systems with private practitioners and groups continuing to provide inpatient and observation care for their patients in the hospital.

The proportion of patients hospitalized for observation status ranged from $25 \%$ to $53 \%$, with an average daily census ranging from 12 to 48 patients, and average LOS ranging from 
26.7 to 39.2 hours (see Table 2). Overall, $11 \%$ to $27 \%$ of patients underwent at least one status change, with $14 \%$ to $91 \%$ of them changing from outpatient (observation services) to inpatient status, and $9 \%-86 \%$ undergoing a status change from inpatient to outpatient observation services. All hospitals lacked a systematic method of monitoring key metrics for observation services, and none had a routine system of disseminating metrics to the stakeholders and front-line staff providing care.
Our evaluation of the patient status assignment process through 175 interviews, chart reviews, and observation of staff revealed several common factors influencing accurate patient status assignment and the level of efficiency of observation care service delivery. Though the chart review was a multidisciplinary effort, there was $100 \%$ concordance between the reviewers because all used the same criteria for auditing charts: presence or absence of medical necessity documentation.

Table 2. Pre- and post-intervention results

\begin{tabular}{|c|c|c|c|c|c|c|c|c|c|c|c|c|c|c|}
\hline & \multicolumn{2}{|c|}{ Hospital 1} & \multicolumn{2}{|c|}{ Hospital 2} & \multicolumn{2}{|c|}{ Hospital 3} & \multicolumn{2}{|c|}{ Hospital 4} & \multicolumn{2}{|c|}{ Hospital 5} & \multicolumn{2}{|c|}{ Hospital 6} & \multicolumn{2}{|c|}{ Hospital 7} \\
\hline & Pre & Post & Pre & Post & Pre & Post & Pre & Post & Pre & Post & Pre & Post & Pre & Post \\
\hline $\begin{array}{l}\% \text { Total OBS } \\
\text { Hospitalizations* }\end{array}$ & 31 & 18 & 53 & 17 & 27 & 11 & 25 & 19 & 53 & 19 & 27 & 13 & 49 & 20 \\
\hline $\begin{array}{l}\text { Accuracy of initial Status } \\
\text { assignment, } \%^{*}\end{array}$ & 57 & 88 & 69 & 91 & 59 & 89 & 23 & 93 & 62 & 94 & 31 & 80 & 54 & 84 \\
\hline $\begin{array}{l}\% \text { of patients undergoing } \geq \\
1 \text { status change }{ }^{*}\end{array}$ & 43 & 12 & 31 & 9 & 41 & 11 & 77 & 7 & 38 & 6 & 69 & 20 & 46 & 16 \\
\hline $\begin{array}{l}\text { Inpatient to OBS } \\
\text { conversions, \%* }\end{array}$ & 86 & 23 & 58 & 8 & 34 & 15 & 32 & 13 & 38 & 12 & 85 & 9 & 68 & 6 \\
\hline $\begin{array}{l}\text { Charts with Medical } \\
\text { Necessity } \\
\text { Documentation, } \%^{* *}\end{array}$ & 31 & 93 & 22 & 73 & 39 & 88 & 26 & 92 & 41 & 86 & 42 & 78 & 48 & 67 \\
\hline Average Daily OBS Census & 12 & 7 & 22 & 8 & 13 & 6 & 34 & 26 & 48 & 17 & 17 & 8 & 20 & 9 \\
\hline $\begin{array}{l}\text { Reduction in OBS LOS, } \\
\text { hours }\end{array}$ & 39 & 27 & 27 & 22 & 33 & 26 & 28 & 18 & 38 & 26 & 37 & 20 & 36 & 23 \\
\hline $\begin{array}{l}\text { Estimated Lost Revenue/ } \\
\text { Actual Revenue, Annually, } \\
\text { \$Million }\end{array}$ & -2.2 & +3.2 & -4.8 & +6.3 & -2.1 & +2.5 & -3.9 & +4.6 & -16.8 & +20.8 & -1.9 & +3.8 & -4.6 & +5.6 \\
\hline
\end{tabular}

Note $^{*} p<.0001$ for change between pre- and post-intervention data, at each hospital; ${ }^{* *} p<.0001$ for change between pre- and post-intervention data for total across all 7 hospitals.

\subsection{Interviews}

\subsubsection{Payor relations}

Interviews with utilization review and revenue cycle staff revealed that physician attestation of the patient's medical necessity, severity of illness, intensity of services, and patient prognosis commonly were overruled by insurers. We found that patient status was often changed to match the insurance company's determination. Each hospital had at least one insurer who insisted that all patients begin as observation status. In the instances of reimbursement denials, utilization review and denial management staff consistently reported that (1) most insurers utilized the patients' clinical course during the entire hospital stay to re-assign them to observation patient status, instead of relying on only the information available to the admitting physician at the time of the decision to hospitalize; and (2) that insurance companies universally asserted their chart review as sufficient evidence to over-ride the judgment of the admitting physician. Finally, at each Published by Sciedu Press hospital, we found numerous instances of private insurers, including Medicare Advantage Plans, denying payment to hospitals, unless patient status was changed to observation after discharge, a practice not permitted by CMS.

\subsubsection{Knowledge gap and documentation}

Medical staff from various backgrounds (Emergency Medicine, Internal Medicine, and Family Medicine) and care/utilization managers displayed a significant knowledge gap in the fundamental definitions of patient status and its determination, clinical documentation needs for patient status justification, regulatory requirements for patient status assignment, and denial avoidance. Four of the seven hospitals had physician advisors, but there was no regular training on this subject offered to the medical staff in any of the hospitals. Physician advisors, when present, were part-time and involved mainly in higher-level reviews or denials management. In each hospital, clinical documentation specialists, or care/utilization management nurses were charged with pro- 
viding on-going, case-by-case, documentation guidance for medical staff. Usually, care/utilization managers thought that patient status was determined primarily by whether or not a patient met criteria established by InterQual $(\mathrm{R}$ or Milliman Care Guidelines, and that insurance companies set the gold standard definition of patient status. In contrast, medical providers universally reported screening guidelines such as Milliman Care Guidelines and InterQual $®$ frequently did not accurately classify the patient status, and often did not even have the diagnosis available in their guidelines.

The care/utilization management staff at each hospital strictly applied clinical criteria guidelines (e.g., InterQual $®$, Milliman Care Guidelines) to issue verbal recommendations to physicians for patient status assignment. Physicians and advanced practice professionals (APPs) most frequently reported that that they had relegated the final decision of patient status assignment to care/utilization management staff, and nearly always implemented their recommendation because they had been told too many inherently contradictory rules for assigning patient status. The second most common reason cited at each hospital was physicians and/or APPs stated that they wished to avoid the stigma of not being a "team player" or "committing fraud" if they did not follow recommendations made by utilization review or care managers. The medical staff usually did not have an expert medical resource to assist in choosing patient status. Though some hospitals did have physician advisors, their part-time availability was a barrier to the on-demand need, especially during peak times of admissions.

Denials were primarily due to the lack of medical necessity justifying the LOS, and care managers and utilization review nurses characterized this as "incomplete physician documentation". The electronic medical chart had all the data necessary to justify a particular patient status choice, but often it was not summarized in the medical admission note, hence lending some credence to the assertion that "medical documentation does not justify the chosen status." Uniformly, medical admission notes utilized elaborate templates, with references to a database of labs and historical documents. However, over $64 \%$ (range, $52 \%-78 \%$ ) of charts lacked documentation of medical necessity.

Itemized problems for medical management were documented; and the medical staff uniformly felt that, when taken as a whole, these diagnoses and problem lists with attendant plans for treatment sufficiently portrayed the severity of illness and intensity of services delivered. They reported time constraints as the main reason for omitting an explanation of the correlation of pathophysiologic basis for the illness to the estimated LOS for its treatment, and outcomes necessary for discharge readiness.

\subsubsection{Communication and handoffs}

Hospitalists consistently reported the handoff from ED was insufficient for the accurate determination of patient status, often inaccurately portraying the severity of illness or length of treatment estimated for discharge readiness. ED providers did not want the responsibility of determining patient status, which they considered a distraction from more pressing clinical duties. Generally, there was a lack of appreciation by both emergency and hospitalist medical staff for the clinical, psychological and financial impact of accurate status designation on the patient and hospital, with a general belief that patients can be placed on observation status and later changed to inpatient by utilization review staff. Finally, none of these hospitals had a multidisciplinary "huddle" for observation patients in the hospital, where medical provider, nurse, social worker, and utilization/care manager can all debrief each other and review the care-plan of day.

\subsection{Staffing and workflow}

We consistently found the absence of a clinical leadership team with the authority or responsibility to monitor and advance the needs of observation patient services. When a medical leader was identifiable, there was no dedicated time allotted for this administrative activity, which was superimposed on simultaneous clinical care responsibilities. Observation patients were often scattered throughout the hospital, without dedicated medical providers. As a result, medical providers were often ethically torn between seeing lesser-sick observation patients before the more acutely-ill inpatients: no matter which decision they made, they reported being criticized by their supervisors. In each hospital, the direct patient care and support staff did not have a sense of urgency for the pace of observation service delivery. The aforementioned lack of dedicated medical and care-management staff to care for observation patients, even in a scatter bed distribution, was compounded by several operational issues: the lack of medical provider(s) dedicated solely to the observation unit; lack of on-site nocturnist medical staff and delayed daytime medical rounds; insufficient communication between the medical provider, nurse and care manager; the lack of prioritization of medical testing for observation patients; high utilization of subspecialty consultations, physical therapy, and occupational therapy evaluations; and inadequate updates on the care plan throughout the day.

\subsection{Geography}

None of the hospitals had a uniform care paradigm for observation patients in a dedicated observation unit. Three hospitals which had dedicated observation units actually had more inpatients than observation patients in those units while continuing to have observation patients on other medical units. 
Hospital personnel responsible for patient placement into beds had competing priorities for bed assignment between expediting throughput out of the ED and cohorting observation patients, causing a co-mingling of observation patients with inpatients in a scatter-bed distribution throughout the hospital. Unfortunately, though it improves ED throughput, the co-mingling of inpatients and observation patients contributed to the increase in LOS of patients receiving observation services.

\subsection{Operational outcomes}

We achieved significant decreases in the proportion of patients assigned to observation services $(38 \%$ to $17 \%, p<$ $.001)$. The accuracy of initial status assignment improved $(50.7 \%$ to $88.4 \%, p<.001)$, and medical necessity documentation increased from $35.6 \%$ to $82.4 \%(p<.001)$. There was a decrease in the proportion of hospitalized patients undergoing any status change $(49.3 \%$ to $11.6 \%, p<.001)$, and in the percent of patient undergoing conversion from inpatient to observation services $(57.3 \%$ to $12.3 \%, p<.001)$. We also observed a decline in the average observation patients LOS (from 34 to 23 hours), and average daily observation census (from 24 to 12 patients), across all hospitals. Each hospital achieved a financial improvement; the actual annual post-intervention gain ranged from $\$ 2.5 \mathrm{M}$ to $\$ 20.8 \mathrm{M}$ (see Table 2).

\section{Discussion}

Our report demonstrates a significant financial impact due to a high proportion of incorrect patient status assignment upon hospitalization at seven hospitals of variable size, with overuse of outpatient status for observation services and high frequency of status conversions. This was principally due to insufficient documentation for justifying the chosen patient status. Our interviews revealed that the incorrect determination of patient status, at the time of hospitalization from the ED not only utilized significant resources of the medical, social work and care/utilization management staff but has significant financial consequences for the hospital and often also the patient. It often led to placement of patients into the wrong clinical setting, with a pace of care that was not suited to patients' needs. This misclassification may be due to a poor understanding of the definitions of medical necessity, observation services, and inpatient status by the various patient care-team members.

Implementation of our bundle of interventions led to statistically significant fewer patients with an incorrect status assignment and fewer status conversions, especially from inpatient to observation care. A cornerstone of our intervention was to empower medical staff to determine patient status using medical necessity and complex medical decision mak-

Published by Sciedu Press ing by documenting their clinical reasoning explicitly; the presence of medical necessity documentation also showed a significant improvement. Our educational series established a baseline vocabulary for communicating patient status and documenting medical necessity uniformly within the patient care team. Additionally, we harnessed the power of the electronic medical record to generate "smart-phrases" with key prompts to ensure adequate documentation for the justification of both observation services and inpatient status.

We found relatively higher baseline LOS for observation patients than projected by CMS. Numerous factors contributed to a prolonged LOS: including, lack of medical and care/utilization management staff dedicated to observation patient care, lack of geographic cohorting of observation patients, low priority assigned to tests for observation patients, lack of multidisciplinary rounds, and frequent subspecialty, physical therapy and occupational therapy consultations. Our bundle addressed each of these factors by re-configuring medical, nursing, care management and utilization review staff to give focused attention to observation patients. We empowered other care team members to work with medical staff to prioritize observation service delivery in the hospital and expedite linkage to ambulatory services in the primary care setting.

Our interventions resulted in large financial gains at each institution. The recovery of lost revenue by assigning justifiable inpatient status, together with improved integrity of medical necessity documentation contributed to a reduction in denials. Additionally, our bundle of interventions led to a reduction in staff time consumed by status conversions, denials management and an improved appeals process, more efficient bed utilization, and the decompression of the ED. However, the added benefit of these were not monetarized in our estimated revenue lost or gained.

Our literature search did not identify any reports of the impact of the accuracy of patient status designation on the operational and financial performance of observation services. There is a single report of similar interventions in a single hospital system, ${ }^{[15]}$ which described how to optimize the affordability of observation services and reported financial gains, but did not assess medical necessity documentation. The strengths of this report are that we utilized the same multidisciplinary interventions in seven hospitals of various sizes and in different geographic regions of the United States. Our bundle involved administrative and technologic solutions to empower clinicians to document their clinical reasoning, while allowing care/utilization management staff to use proprietary screening guidelines to further bolster the choice of a particular patient status. 


\section{Limitations}

There are several limitations inherent in our report. Foremost, there is no gold standard, universal definition for attributing patient status, and private insurers do not always apply the 2-midnight rule adopted by CMS. There are no national benchmarks for goals for each of the metrics. Clinical documentation assessments are based on a relatively low number of charts. Our multifaceted bundle of interventions makes it difficult to attribute an outcome to a particular component of the bundle.

\section{Conclusions}

We identified a significant financial loss to hospitals of all sizes, due to misclassification of patient status for a multitude of reasons. Our data show that interventions for improvements in documentation and operational enhancements both contributed to significant financial gains. As hospitals continue to face economic pressure, especially in the COVID19 pandemic, documenting medical necessity and optimal configuration of observation care systems can have a large impact on their narrow operating margins, and may allow a failing hospital to become viable again.

\section{CONFLiCTS OF InTEREST DisClOSURE}

The authors declare they have no conflicts of interest.

\section{REFERENCES}

[1] Centers for Medicare and Medicaid Services, Outpatient observation services. Medicare Claims Processing Manual, Chapter 4-Part B: Hospital, Section 290. Rev. 3556, 07-0116. July 1, 2016 [Accessed August 7, 2020]. Available from: https://www.cms.gov/Regulations-and-Guidance/ Guidance/Manuals/downloads/clm104c04.pdf

[2] Chang AM, Hollander JE, Su E, et al. The accuracy of Interqual Criteria in Determining the Obsrevation versus Inpatient Status in Older Adults with Syncope. J Emergency Medicine. 2020; 59: 193200. PMid: 32291127. https ://doi .org/10.1016/j.jemermed .2020 .02 .020

[3] Society of Hospital Medicine Public Policy Committee. The Hospital Observation Care Problem. September 2017 [Accessed August 7, 2020]. Available from: https://www.hospitalmedicine.org /globalassets/policy-and-advocacy/advocacy-pdf/shm s-observation-white-paper-2017

[4] Centers for Medicare and Medicaid Services HHS. Fact Sheet Two-Midnight Rule. October 30, 2015 [Accessed August 7, 2020]. Available from: https://www.cms.gov/newsroom/fact-she ets/fact-sheet-two-midnight-rule-0

[5] MCG Website. Accessed February 28, 2021. Available from: https //www.mcg.com/care-guidelines

[6] InterQual $($ Website. Accessed February 28, 2021. Available from: https://www. changehealthcare.com/solutions/cli nical-decision-support/interqual

[7] Feng Z, Wright B, Mor V. Sharp rise in Medicare enrollees being held in hospitals for observation raises concerns about causes and consequences. Health Affairs. 2012; 31: 1251-1259. PMid: 22665837. https://doi.org/10.1377/hlthaff.2012.0129

[8] Zhao L, Schur C, Kowlessar N, et al. Rapid growth in Medicare hospital observation services: What's going on? September 2013 [Accessed August 7, 2020]. Available from: https://www . aarp.o $\mathrm{rg} /$ content/dam/aarp/research/public_policy_institu te/health/2013/rapid-growth-in-medicare-hospital-o bservation-services-AARP-ppi-health.pdf
[9] Wright B, O'Shea AMJ, Ayyagari P, et al. Observation rates at veterans' hospitals more than doubled during 2005-13, similar to Medicare trends. Health Affairs. 2015; 34: 1730-1737. PMid: 26438750. https://doi .org/10.1377/hlthaff . 2014.1474

[10] Nuckols TK, Fingar KR, Barrett M, et al. The Shifting Landscape in Utilization of Inpatient, Observation, and Emergency Department Services Across Payers. J of Hospital Medicine. 2017; 12: 443-446. PMid: 28574534. https://doi.org/10.12788/jhm. 2751

[11] Lind KD, Noel-Miller CM, Sangaralingham LR, et al. Increasing Trends in the Use of Hospital Observation Services for Older Medicare Advantage and Privately Insured Patients. Medical Care Research and Review. 2017; 76(2): 229-239. PMid: 29148348. https://doi.org/10.1177/1077558717718026

[12] Figueroa JF, Burke GL, Zheng J, et al. Trends in Hospitalization vs Observation Stay for Ambulatory Care-Sensitive Conditions. JAMA Intern Med. 2019; 179(12): 1714-1716. PMid: 31449290. https ://doi.org/10.1001/jamainternmed.2019.3177

[13] Dharmarajan K, Qin L, Bierlein M, et al. Outcomes after observation stays among older adult Medicare beneficiaries in the USA: retrospective cohort study. British Medical Journal. 2017; 357: j2616. PMid: 28634181. https://doi .org/10.1136/bmj · j2616

[14] Sabbatini AK, Wright B, Hall KM, et al. The cost of observation care for commercially insured patients visiting the emergency department. American J of Emergency Medicine. 2018; 36: 1591-1596. PMid: 29366657. https://doi.org/10.1016/j.ajem.2018.01.040

[15] Basaly RB, Volkmar L, Szewczyk K, et al. How Orlando Health improved its bottom line by optimizing observation services. Healthcare Financial Management Association, June 15, 2020 [Accessed Feb 1, 2020].

[16] Agresti A, Coull B. Approximate is better than 'exact' for interval estimation of binomial proportions. The American Statistician. 1998; 52, 119-126. https://doi.org/10.1080/00031305.199 8.10480550

[17] Altman, DG, Bland, JM. How to obtain the $P$ value from a confidence interval. BMJ. 2011; 343: d2304. PMid: 22803193. https : //doi.org/10.1136/bmj.d2304 